\title{
Ecological and energy efficiency of insulating systems
}

\author{
Aleksey Zhukov ${ }^{1}$, Andrey Medvedev ${ }^{1}$, Alexey Poserenin ${ }^{2}$, and Boris Efimov ${ }^{1}$ \\ ${ }^{1}$ Moscow State University of Civil Engineering, Yaroslavskoe shosse, 26, Moscow, 129337, Russia \\ ${ }^{2}$ Russian State Geological Prospecting University, Miklukcho-Maklaya, 23, Moscow, 117997, Russia
}

\begin{abstract}
The article, on the example of pipeline insulation systems, outlines the fundamentals of the concept of environmentally sustainable construction, including requirements for materials, constructional systems in which these materials are used, engineering systems and work technologies. Insulation based on polyethylene foam technology of its installation meets the requirements of EcoMaterial Basis or EcoMaterial Green. Polyethylene is absolutely safe for humans and its base is polyethylene, which used in the food industry (packaging or boxing) and in medicine (prosthetics). A specific feature of polyethylene foam, like most types of foamed (gas-filled) plastic materials, is combustibility, expressed depending on the consumption and effectiveness of flame retardants, to one degree or another. During operation in the temperature range from -60 to $+90{ }^{\circ} \mathrm{C}$, the properties of materials are stable and no harmful emissions occur. The installation of the insulating sheath fixed by an glue method and is not associated with processes that are dangerous for humans and harmful to the environment. The article presents the main provisions of methods for calculating insulation systems based on polyethylene by measure of energy efficiency, which is defining, including the environmental assessment of insulation systems. The optimum thickness of polyethylene foam has been determined, as well as the recommended insulation thicknesses to ensure a given (safe for humans) temperature; to prevent moisture condensation on the surface of the insulating layer. An calculated time has been established during which thermal insulation prevents cold water from freezing when at an emergency stop of its movement in pipelines in the winter.
\end{abstract}

\section{Introduction}

The concept of environmentally sustainable construction (EUS) includes requirements for materials, construction systems in which these materials are used, engineering systems and technology of work. The basis for any system solutions and implementation of EUS projects is the availability of materials compliant with EcoMaterial standards. The basis of the voluntary certification system for the construction industry "Eco Material" is the environmental rating standard EcoMaterial 1.3. The standard was compiled on the basis of

* Corresponding author: medvedev747@yandex.ru 
legislative acts of the Russian Federation, ISO 14024, advanced developments of the World Health Organization, recommendations of international organizations on "green building", standards DGNB, BREEAM and LEED [1-6].

There are several levels of the standard depending on the points obtained and the characteristics of the materials: EcoMaterial Basis - the material is safe for humans; EcoMaterial Green - the material is safe for humans and the environment; EcoMaterial Absolut - environmentally friendly material; EcoMaterial Natural is an absolutely natural material (the highest rated, with the most points). Insulating materials that meet the standards of "Eco Material" should have a low thermal conductivity, do not contain substances hazardous to health, while maintaining performance characteristics regardless of operating conditions [7-10]. Technological processes are organized in such a way as to minimize the negative impact on the environment. Saving heat by reducing losses through an insulating jacket should, in an economically feasible time, recoup the energy costs of manufacturing materials and installing them in insulation systems [11-13]. Products from unstitched expanded polyethylene (pipes, rolls, sheets) have been used as insulation since the beginning of the 90s and now we have gained sufficient experience for use of them. The material of the products is resistant to aggressive media, has increased strength, moisture resistance and durability, effectively reduces heat loss and structural noise, protects the surface of the equipment from condensate and corrosion, interferes with freezing of the heat carrier for a specified time. Maximum operating temperature up to $+95{ }^{\circ} \mathrm{C}$; thermal conductivity coefficient at $10 / 20 / 30{ }^{\circ} \mathrm{C} 0.038 / 0.039 / 0.040 \mathrm{~W} /(\mathrm{m} \cdot \mathrm{K})$; water vapor diffusion resistance factor 6000 - 9000; combustibility group G1 or G2, depending on the version [14-17].

Insulating materials made of polyethylene foam are used for thermal insulation of heating systems, hot and cold water supply, ventilation and air conditioning systems, sanitary systems, enclosing structures in industrial and engineering systems. Technical insulation made of polyethylene foam is ideal for effective heat, steam and noise insulation of pipes of different diameters, capacity and fittings in water supply and heating systems, sewage systems, as well as enclosing structure.

When using thermal insulation of polyethylene inside buildings and structures there is no need to use vapor barrier and coating layers. The material is environmentally friendly, safe at work, does not require personal protective equipment. The peculiarity of the material is its combustibility and low resistance to ultraviolet exposure.

In insulating structures on pipelines, heat insulation products in the form of tubes are used as heat insulation, and in the absence of the required size in the manufactured nomenclature of tubes, heat insulation products in the form of rolls. Products can be made without coating or with a protective coating: flexible, based on glass mesh, coated on the basis of metallized lavsan, with a foil surface, steel or aluminum. As well as used coating of aluminum sheets or strips, or galvanized steel with a thickness of $0.5-0.8 \mathrm{~mm}$, depending on the outer diameter of the insulating structure. A modern approach to standardizing the thermal protection of pipelines or energy facilities is based on the consideration of an object as a complete energy system, the efficiency of which is evaluated according to the criterion of energy efficiency. In accordance with the regulatory requirements of SR 61.13330.2012, thermal insulation structures should meet energy efficiency requirements: they must have an optimal balance between the cost of the thermal insulation structure and the cost of heat losses through thermal insulation during the design life. The calculation of the thermal insulation design by energy efficiency is carried out to determine the thickness of the thermal insulation according to the minimum cost depending on the type of foam- 
polyethylene products, the type of coating material, the lifetime of the thermal insulation structure and the cost of thermal energy.

The calculation of the energy-efficient thickness of the insulation $\left(\mathrm{E}_{\mathrm{year}}\right)$ is carried out taking into account the cost of the thermal insulation construction $1 \mathrm{~m}$ of the pipeline length taking into account the transportation $\left(S_{\mathrm{k}}, \mathrm{rub} / \mathrm{m}\right)$; the cost of products and materials included in the thermal insulation structure of $1 \mathrm{~m}$ pipeline length, $\left(S_{\mathrm{p}}, \mathrm{rub} / \mathrm{m}\right)$. The calculation condition is expressed by the dependency:

$$
\mathrm{E}_{\text {year }}=\left(p+p_{\mathrm{n}}\right) S_{\mathrm{k}}+S_{\mathrm{t} . \mathrm{i}}=\text { minimum }
$$

The coefficient determining the value of annual operating costs on insulation in shares of the total cost of the thermal insulation structure (p) is determined taking into account the service life of the thermal insulation structure $(\tau$, year) and the coefficient determining the cost of maintenance and repair of the insulation for the entire service life in shares of the cost of thermal insulation design (m) by the formula: $p=\frac{(1+m)}{\tau}$. The regulatory efficiency ratio of capital investments $\left(p_{n}, 1 /\right.$ year). Is defined as the value inverse to the standard operating life $p_{n}=\frac{1}{T_{n}}$.

\section{Materials and Methods}

The cost of thermal insulation design per $1 \mathrm{~m}$ pipeline length, taking into account the cost of thermal insulation construction $1 \mathrm{~m}$ pipeline length including transport and installation $\left(\mathrm{S}_{\mathrm{k}}\right)$; the cost of products and materials included in the thermal insulation structure of $1 \mathrm{~m}$ pipeline length $\left(\mathrm{S}_{\mathrm{p}}\right)$; the cost of transporting products and materials included in the insulating structure of $1 \mathrm{~m}$ pipeline length $\left(\mathrm{S}_{\mathrm{tr}}\right)$ and cost of installation of thermal insulation design for $1 \mathrm{~m}$ of pipeline length $\left(\mathrm{S}_{\mathrm{in}}\right)$ is determined by the formula:

$$
S_{\mathrm{k}}=S_{\mathrm{p}}+S_{\mathrm{tr}}+S_{\mathrm{in}}
$$

Table 1. The thickness of the heat-insulating layer of products made of polyethylene without coating

\begin{tabular}{|c|c|c|c|c|}
\hline \multirow{5}{*}{$\begin{array}{l}\text { Outer diameter of the } \\
\text { pipeline or } \\
\text { equipment, } \mathrm{mm}\end{array}$} & \multicolumn{4}{|c|}{ Number of hours of work per year } \\
\hline & \multicolumn{2}{|c|}{5000 and less } & \multicolumn{2}{|c|}{ more 5000} \\
\hline & \multicolumn{4}{|c|}{$\begin{array}{l}\text { Estimated coolant temperature, }{ }^{\circ} \mathrm{C} \text {, for the temperature regime of heat } \\
\text { networks } 95-70{ }^{\circ} \mathrm{C}\end{array}$} \\
\hline & $\begin{array}{l}50 \text { (return } \\
\text { pipeline) }\end{array}$ & 65 (direct pipeline) & $\begin{array}{l}50 \text { (return } \\
\text { pipeline) }\end{array}$ & 65 (direct pipeline) \\
\hline & \multicolumn{4}{|c|}{ The thickness of the insulating layer, $\mathrm{mm}$} \\
\hline 15 & $13^{t}$ & $13^{\mathrm{t}}$ & $13^{\mathrm{t}}$ & $13^{t}$ \\
\hline 30 & $13^{\mathrm{t}}$ & $13^{\mathrm{t}}$ & $20^{t}$ & $20^{\mathrm{t}}$ \\
\hline 54 & $20^{t}$ & $20^{\mathrm{t}}$ & $20^{t}$ & $20^{\mathrm{t}}+10^{\pi}$ \\
\hline 89 & $20^{t}$ & $13^{\mathrm{t}}+10^{\mathrm{sh}}$ & $13^{\mathrm{t}}+13^{\mathrm{sh}}$ & $20^{t}+10^{\text {sh }}$ \\
\hline 160 & $13^{\mathrm{t}}+10^{\mathrm{sh}}$ & $13^{\mathrm{t}}+13^{\mathrm{sh}}$ & $13^{\mathrm{t}}+13^{\mathrm{sh}}$ & $20^{\mathrm{t}}+13^{\mathrm{sh}}$ \\
\hline 426 & $13^{\mathrm{sh}}+10^{\mathrm{sh}}$ & $13^{\text {sh }}+13^{\text {sh }}$ & $13^{\text {sh }}+13^{\text {sh }}$ & $20^{\text {sh }}+13^{\text {sh }}$ \\
\hline 820 & $13^{\mathrm{sh}}+10^{\mathrm{sh}}$ & $13^{\text {sh }}+13^{\text {sh }}$ & $13^{\text {sh }}+13^{\text {sh }}$ & $20^{\mathrm{sh}}+13^{\mathrm{sh}}$ \\
\hline 920 & $13^{\text {sh }}+10^{\text {sh }}$ & $13^{\text {sh }}+13^{\text {sh }}$ & $13^{\text {sh }}+13^{\text {sh }}$ & $20^{\text {sh }}+13^{\text {sh }}$ \\
\hline 1020 & $13^{\mathrm{sh}}+10^{\mathrm{sh}}$ & $13^{\mathrm{sh}}+13^{\mathrm{sh}}$ & $13^{\mathrm{sh}}+13^{\mathrm{sh}}$ & $20^{\mathrm{sh}}+13^{\mathrm{sh}}$ \\
\hline More 1020 & $13^{\text {sh }}+13^{\text {sh }}$ & $13^{\text {sh }}+13^{\text {sh }}$ & $13^{\text {sh }}+13^{\text {sh }}$ & $20^{\text {sh }}+13^{\text {sh }}$ \\
\hline
\end{tabular}
in the heat-insulating structures for equipment and pipelines located in the room 
Note - $\mathrm{t}$ - tubes; sh - sheets (rolls).

The cost of materials and products for thermal insulation design for $1 \mathrm{~m}$ of the pipeline length, taking into account the cost of thermal insulation products included in the thermal insulation design of $1 \mathrm{~m}$ pipeline length $\left(S_{\mathrm{t} . \mathrm{i}}\right)$; the cost of glue required for the installation of thermal insulation design of $1 \mathrm{~m}$ length of the pipeline $\left(S_{\mathrm{gl}}\right)$; the cost of the tape, which required for the installation of thermal insulation design of $1 \mathrm{~m}$ length of the pipeline $\left(S_{\mathrm{tp}}\right)$; the cost of the cleaner, which required for the installation of thermal insulation design of $1 \mathrm{~m}$ length of the pipeline $\left(S_{\mathrm{cl}}\right)$ and the cost of the coating included in the thermal insulation structure of $1 \mathrm{~m}$ of the length of the pipeline $\left(S_{\text {coat }}\right)$ is determined by the formula:

$$
S_{\mathrm{p}}=S_{\mathrm{t} . \mathrm{i}}+S_{\mathrm{gl}}+S_{\mathrm{cl}}+S_{\mathrm{tp}}+S_{\text {coat }}
$$

The recommended economical thickness of thermal insulation of polyethylene foam products for pipelines located indoors and outdoors is given in Table 1.

\section{Results}

As a result of the practical implementation of the methods, calculations were carried out and the recommended economical thickness of polyethylene foam in thermal insulation structures for pipelines of heat networks and heating systems (indoors and outdoors) was determined; the recommended thickness of the heat-insulating layer in the heat-insulating structures intended to provide the desired (safe for humans) temperature on the surface of the heat-insulating layer has been determined; the recommended thickness of the heatinsulating layer in heat-insulating structures intended to prevent moisture condensation on the surface of the heat-insulating layer of equipment, pipelines and ducts of ventilation and air-conditioning systems located in the room has been determined. An calculated time has been established during which thermal insulation prevents freezing of cold water with an initial temperature of $5^{\circ} \mathrm{C}, 10^{\circ} \mathrm{C}$ and $15^{\circ} \mathrm{C}$ when at an emergency stop of its movement in pipelines in the winter. The technology for performing insulation works with the use of polyethylene foam products has been developed and outlined, according to which longitudinal and transverse joints of products are glued together with contact glue to fasten the tubes on the pipeline. It is recommended to additionally glue the seams of products reinforced with self-adhesive tape (Fig. 1). 

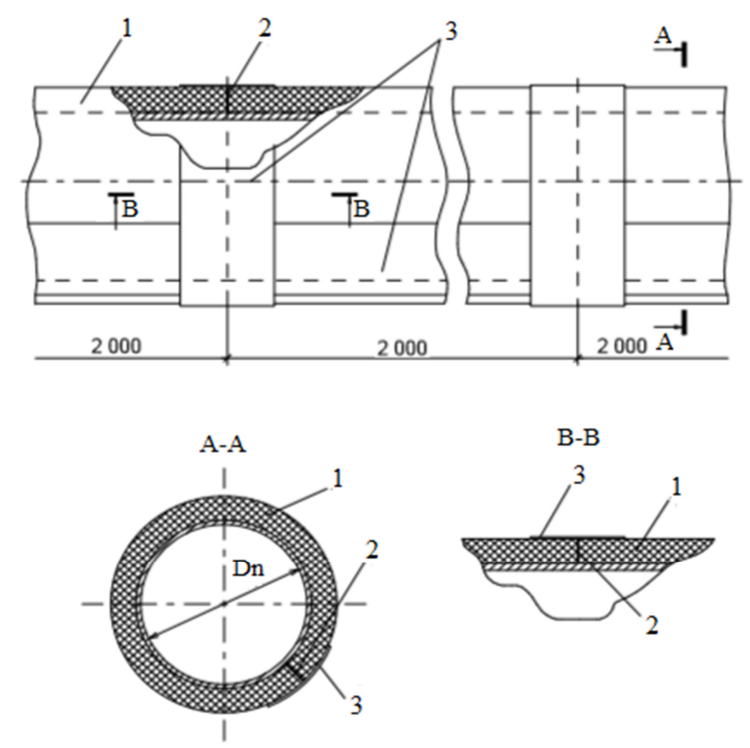

Fig.1. Thermal insulation design of the pipeline with a diameter of Dn: 1 - a tube made of thermal insulation material; 2 - glue; 3 - self-adhesive reinforced tape.

When installed on pipelines of heat-insulating products in the form of rolls or mats, bandages should be arranged in steps of 500 to $600 \mathrm{~mm}$ (Fig. 2).
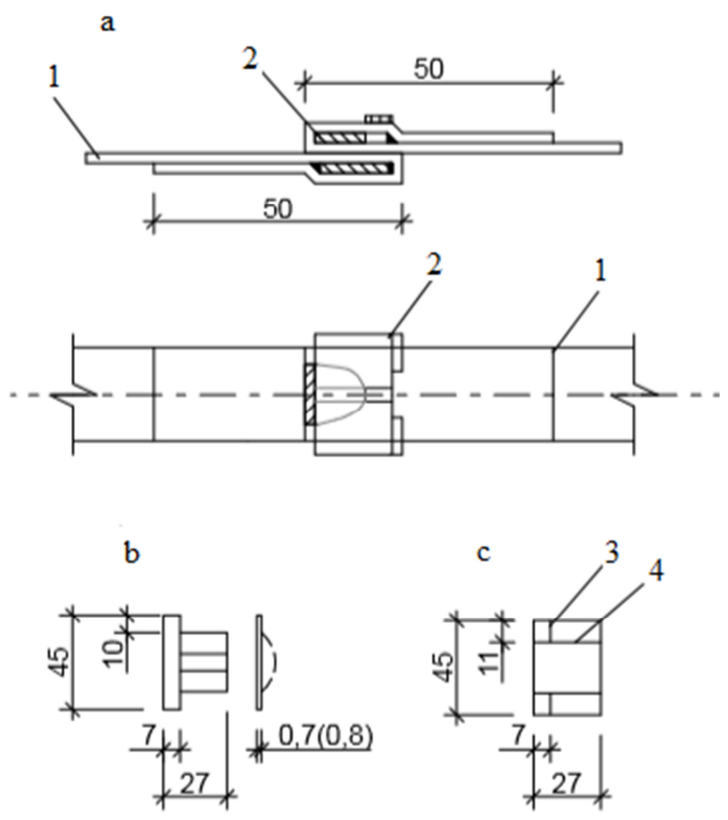

Fig.2 The construction of the bandage: a - buckle; b, c - buckle blank; 1 - bandage; 2 - tape; 3 - cut line; 4 - fold line 

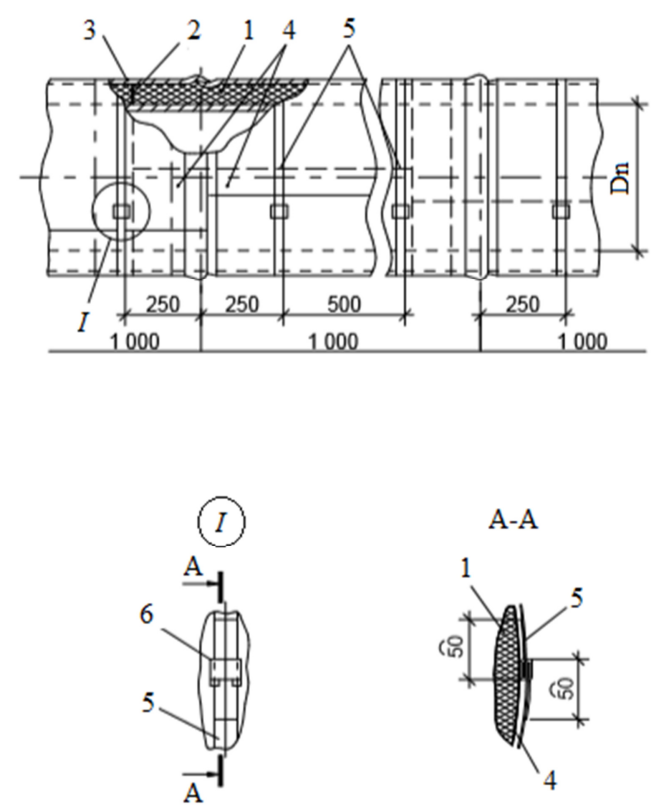

Fig.3 Thermal insulation design with the bandage: 1 - a tube of heat-insulating material with $\mathrm{Dn} \leq$ $160 \mathrm{~mm}$ (sheet of heat-insulating material with $\mathrm{Dn}>160 \mathrm{~mm}$ ); 2 - glue; 3 - self-adhesive reinforced tape; 4 - metal shell; 5 - bandage (with a buckle); 6 - buckle

For bandage, it is allowed to use metal tapes with a corrosion-resistant coating of stainless steel, aluminum alloys or polyamide (Fig. 3). The material of the bandage used for fastening the coating layer should correspond to the material of which the coating is made. The material used to make the buckle (2a) should correspond to the material of which the bandage is made (galvanized or stainless steel, aluminum alloy sheets).

\section{Conclusion}

For thermal insulation of bends, tees, transitions and fittings, it is necessary to produce on the job site heat insulating elements made of products in the form of tubes, cylinders, sheets or mats. For fastening sheets (rolls) on pipelines, the seams of products are glued with contact glue. It is recommended to additionally glue the seams of products reinforced with self-adhesive tape, as well as to fix the products with bandages of reinforced self-adhesive tape located in steps from 500 to $600 \mathrm{~mm}$.

In case the calculated thickness of the heat-insulating layer exceeds the thickness provided for by the nomenclature of polyethylene pipes or sheets (rolls), a two-layer or three-layer system is used. As the second and subsequent layers, it is recommended to use polyethylene sheets (rolls); metallic coated sheets (rolls) can be used only as the outer layer of a multi-layer construction. In multilayer insulating structures designed for pipelines, the installation of the second and subsequent layers of thermal insulation is performed with overlapping joints of each previous layer. The seams of all layers of thermal insulation are glued with contact glue. It is recommended to additionally glue the seams of the outer layer reinforced with self-adhesive tape. The pipelines insulation system using foam polyethylene pipes or mats fully complies with the principles of ecological construction. A specific feature of polyethylene foam, like most types of foamed (gas-filled) plastic materials, is combustibility, expressed depending on the consumption and effectiveness of flame 
retardants, to one degree or another. For other significative material and its installation technology meets the requirements of Eco Material Basis or Eco Material Green. Polyethylene is absolutely safe for humans and its base is polyethylene, which used in the food industry (packaging or boxing) and in medicine (prosthetics). During operation in the temperature range from -60 to $+90^{\circ} \mathrm{C}$, the properties of materials are stable and no harmful emissions occur. The installation of the insulating sheath fixed by an glue method and is not associated with pro-cesses that are dangerous for humans and harmful to the environment. During external insulation work, the insulation sheath is protected with coatings that increase the weather resistance and fire safety of the system.

\section{References}

1. Zhuk P.M., Zhukov A.D., Ecology and Industry of Russia. 4, 52 -57 (2018).

2. Medvedev A., Bobrova E., Poserenin A., Zarmanyan E., MATEC, 170 (2018) DOI: https://doi.org/10.1051/matecconf/201817003018

3. Asamatdinov, M., Medvedev, A. Zhukov, A., Zarmanyan, E., Poserenin, MATEC, 193 (2018) DOI: 10.1051/matecconf/201819303045

4. Pyataev E., Medvedev A., Poserenin A., Burtseva M., Mednikova E., MATEC, (2018) DOI: $10.1051 /$ matecconf $/ 201825101012$

5. Zhukov A.D., Bobrova Ye.Yu., Zelenshchikov D.B., Mustafaev R.M., Khimich A.O, Advanced Materials, Structures and Mechanical Engineering. Vol. 1025-1026, 10311034.

6. Deni Tuchaev, Ervand Zarmanyan, Evgeniy Petrovskiy, Anatoliy Zemlyanko, Kazbek Ivanov and Aleksey Zhukov,, IOP Conf. Series: Materials Science and Engineering. (2018) doi:10.1088/1757-899X/365/3/032015032041 (2018).

7. Zhukov A., Ter-Zakaryan A., Bobrova, E., Bessonov, I., Medvedev, A., Mukhametzyanov V., Poserenin, A. Evaluation of thermal properties of insulation systems in pitched roofs / TPACEE 2018. DOI: 10.1051/e3sconf/20199102047

8. Shoyhet B.M., B.M. Shoykhet, L.V. Stavritskaya, Ya.A. Kovylyansky, Journal "Energy Saving, 5, 43-45 (2002)

9. Zhukov A.D., Bobrova E.Yu., Smirnova T.V. Evaluation of durability of mineral wool products / Advanced Materials, Structures and Mechanical Engineering. 1077, 109-112 (2015).

10. Rumiantcev B.M., Zhukov A.D., Zelenshikov D.B., Chkunin A.S., Ivanov K.K., Sazonova Yu.V. Insulation systems of the building construtions / MATEC Web of Conferences. Vol. 86. DOI: http://dx.doi.org/10.1051/matecconf/ 20168604027. (2016).

11. Zhukov A.D., Konoval'tseva T.V., Bobrova E.Yu., Zinovieva E.A., Ivanov K.K. MATEC, (2018) DOI: https://doi.org/10.1051/matecconf/201825101016.

12. Gnip, I.J., Keršulis, V.J., Vaitkus, S.J. Mechanics of Composite materials. 41, 4, $357-364$ (2005).

13. Zhukov, A.D, Semenov V.S, Gnip, I.J., Vaitkus, S.J. The investigation of expanded polystyrene creep behavior. Proceedings of the XXVI R-S-P Seminar 2017, Theoretical Foundation of Civil Engineering MATEC, 117, 24 (2017).

14. Umnyakova N.P, Tsygankov V.M., Kuzmin V.A. Experimental heat engineering studies for the rational design of wall structures with reflective heat insulation // Housing construction.1-2, 38-42 (2018). 
15. Rumiantcev B.M., Zhukov A.D., Bobrova E.Yu, Romanova I. P., Zelenshikov D.B., MATEC Web of Conferences. 86 (2016) DOI: http://dx.doi.org/10.1051/matecconf/ 20168604036.

16. I. Ilin, O.V. Kalinina, O. Iliashenko, A. Levina, Procedia Engineering, 165, 1673 1682. (2016) doi: 10.1016/j.proeng.2016.11.909

17. A.R. Bril, O.V. Kalinina, I.V. Ilin, A.S. Dubgorn, O.Y. Iliashenko, Forecasting the turnover growth in the risk management system as management decisions support. Proceedings of 2017 20th IEEE International Conference on Soft Computing and Measurements, SCM 2017. Paper number 7970692, 692-693 (2017) DOI: 10.1109/SCM.2017.7970692

18. Rumiantcev B.M., Zhukov A.D., Zelenshikov D.B., Chkunin A.S., Ivanov K.K., Sazonova Yu.V. MATEC Web of Conferences. 86 (2016). DOI: http://dx.doi.org/10.1051/matecconf/ 20168604027

19. Zhukov A.D., Ter-Zakaryan K.A., Tuchaev D.U., Petrovsky E.S., International Agricultural Journal, 1 (361), 65-67 (2018).

20. Zhukov A.D., Efimov B.A., Sazonova Yu.V., Zhukov A.Yu., Scientific Review.7, 1014 (2017) 